\title{
Differences in mental health problems, coping self-efficacy and social support between adults victimised before and adults victimised after the COVID-19 outbreak: population-based prospective study
}

Peter G. van der Velden, Carlo Contino, Marcel Das, Joost Leenen and Lutz Wittmann

\section{Background}

Victims of violence, accidents and threats are at risk for mental health problems. Lower coping self-efficacy and social support levels increase this risk. Although highly relevant, it is unknown if the coronavirus disease 2019 (COVID-19) pandemic amplifies these risks.

\section{Aims}

To examine if the prevalence, incidence and/or mean scores for post-traumatic stress disorder (PTSD), anxiety and depression symptoms, general mental health problems, coping self-efficacy, lack of emotional support and social acknowledgement are higher among adults victimised in the year after the COVID-19 outbreak compared with adults victimised in a similar period before the outbreak. Also, to compare symptoms, problems and support within non-victims during the same period.

\section{Method}

Data was extracted from four surveys of the VICTIMS study (March 2018, 2019, 2020,2021), based on a random sample of the Dutch population. Multivariate logistic regression analyses and mixed-effects models were used to examine differences

between the two victim groups $(2019: n=421,2021: n=319)$ and non-victims $(n=3245)$.

\section{Results}

Adults victimised after the outbreak more often had PTSD, anxiety and depression symptoms, general mental health problems and lower coping self-efficacy than those victimised before. They did not differ in lack of support and acknowledgement. Both victim groups differed from non-victims, where mental health problems and lack of support levels were much lower and almost stable.

\section{Conclusions}

The COVID-19 pandemic had a negative impact on the mental health and coping self-efficacy levels of victims, whereas mental health problems among non-victims remained virtually stable. Mental healthcare workers, general practitioners and victim services should take this impact into account.

\section{Keywords}

COVID-19; PTSD; social support; coping self-efficacy; victims.

\section{Copyright and usage}

(C) The Author(s), 2022. Published by Cambridge University Press on behalf of the Royal College of Psychiatrists. This is an Open Access article, distributed under the terms of the Creative Commons Attribution-NonCommercial-NoDerivatives licence (https://creativecommons.org/licenses/by-nc-nd/4.0/), which permits non-commercial re-use, distribution, and reproduction in any medium, provided the original work is unaltered and is properly cited. The written permission of Cambridge University Press must be obtained for commercial re-use or in order to create a derivative work.

\section{Background}

Each year, a considerable minority of the adult general population is victimised by exposure to violence, accidents and serious threats (VATs). ${ }^{1}$ The effects of these events on the mental health of the victims are well documented. ${ }^{2}$ With respect to risk factors for post-trauma mental health problems, research has shown that lower levels of event-related coping self-efficacy, for example, the perceived ability to cope with post-trauma recovery demands 3 and lower levels of social support are associated with in an increased risk of post-trauma mental health problems. ${ }^{5,6}$

On 11 March 2020, the coronavirus disease 2019 (COVID-19) outbreak was officially declared a pandemic by the World Health Organization. A meta-analysis of longitudinal cohort studies on the effects of this pandemic on the mental health of the general population with pre-outbreak data on mental health, has shown that the overall increase in mental health symptoms was most pronounced during the early stages of the pandemic (March-April 2020), before decreasing and being generally comparable with pre-pandemic levels by mid-2020. ${ }^{7}$ However, even in the absence of enduring effects of the current pandemic on the mental health of the general population, specific subgroups may be less resilient to pandemic- related stressors. As it is known that psychosocial problems such as financial hardship or lack of social support can increase the impact of potentially traumatic events, ongoing COVID-19 pandemicrelated stressors (for example lockdowns, infection and health risks, unemployment risk) may substantially disturb or hinder the normal recovery process of victims. ${ }^{8,9}$ Yet, to the best of our knowledge, to date no study has compared adults victimised during the COVID-19 pandemic with adults victimised in a similar time span before this pandemic. Insight into these effects is relevant for mental healthcare professionals and policymakers.

\section{Aims}

To fill this gap, the present population-based study compared the mental health (anxiety and depression symptoms, post-traumatic stress disorder (PTSD) symptoms, general mental health problems), event-related coping self-efficacy and lack of social support (lack of emotional support and social acknowledgement) of adults victimised by VATs before the outbreak (group $1^{\text {victims: }}$ : victimised between March $2018\left(T_{1}\right)$ and March $2019\left(T_{2}\right)$ ) with adults victimised by VATs in the year after the outbreak of COVID-19 
(group $2^{\text {victims }}$ : victimised between March $2020\left(T_{3}\right)$ and March $\left.2021\left(T_{4}\right)\right)$.

To examine the extent to which this pandemic specifically affects victims, we also examined the patterns of anxiety and depression symptoms, general mental health problems, and lack of emotional support among respondents in March 2019 and March 2021 not victimised by VATs between March 2018 and March 2021(i.e. non-victims).

\section{Method}

\section{Procedures and participants}

For the present study, data was extracted from four waves of the prospective VICTIMS study ${ }^{1,6}$ conducted in March 2018 $\left(T_{1} ; n^{\text {invited }}=7292\right.$, response 82.1\%), March $2019\left(T_{2} ; n^{\text {invited }}=6298\right.$, response $83.2 \%)$, March $2020\left(T_{3} ; n^{\text {invited }}=6568\right.$, response $\left.83.6 \%\right)$ and March $2021\left(T_{4} ; n^{\text {invited }}=6452\right.$, response 86.7\%).

The VICTIMS study was conducted using the Longitudinal Internet Studies for the Social Sciences (LISS) panel, based on a traditional probability sample drawn from the Dutch population register of 16 years and older by Statistics Netherlands. The set-up of LISS was funded by the Dutch Research Council (NWO) and managed by Centerdata. ${ }^{10}$ Panel members complete online questionnaires every month, which take about $30 \mathrm{~min}$ in total to complete. They receive an incentive of 15 euros per $h$ and members who do not have a computer and/or internet access are provided with the necessary equipment at home (for further information about the LISS panel and open access data see: https://www.dataarchive.lissdata.nl, in English). The authors assert that all procedures contributing to this work comply with the ethical standards of the relevant national and institutional committees on human experimentation and with the Helsinki Declaration of 1975, as revised in 2008. All procedures were approved by an Internal Review Board of Centerdata. Explicit digital informed consent was obtained from all respondents.

\section{Victims}

We first compared the two victim groups: respondents victimised between March 2018 and March 2019 (group $1^{\text {victims }}$ ) and respondents victimised between March 2020 and March 2021 (group $2^{\text {victims }}$. For group $1^{\text {victims }}$, we linked data on mental health and lack of support assessed at $T_{1}$ (before victimisation between $T_{1}$ and $T_{2}$ ) and for group $2^{\text {victims }}$ we linked the same data assessed at $T_{3}$ (before victimisation between $T_{3}$ and $T_{4}$ ).

Preliminary analyses showed that 105 respondents were victimised between $T_{1}$ and $T_{2}$, as well as between $T_{3}$ and $T_{4}$, prohibiting an independent comparison between both victim groups. To solve this problem, we randomly divided this subgroup into two subgroups. One-half $(n=52)$ was added to the group of respondents who participated at $T_{1}$ and $T_{2}$ (group $\left.1^{\text {total }}, n=4717\right)$ and the other half $(n=53)$ to respondents who participated at $T_{3}$ and $T_{4}$ (group $2^{\text {total }}, n=4875$ ). In this way, the proportion of group $1^{\text {victims }}$ and group $2^{\text {victims }}$ is similar (56\% versus $44 \%$ ) to the original proportion of people with VAT cases in between $T_{1}$ and $T_{2}$, and in between $T_{3}$ and $T_{4}$.

Next, we weighted the data of group $1^{\text {total }}$ and group $2^{\text {total }}$ using 16 exclusive demographic profiles among the total adult Dutch population (2018 and 2020 respectively), based on the data of Statistics Netherlands (see: https://opendata.cbs.nl/\#/CBS/en/). These profiles were constructed using the variables gender (male, female), age (18-34, 35-49, 50-64, 65 years and older) and marital status (married and unmarried). After this procedure and weighting, we finally selected the victims of group $1(n=421)$ and the (non-overlapping) victims of group $2(n=319)$.

\section{Non-victims}

To examine differences in mental health and social support among non-victims before and after the outbreak, we assembled a second data-set. For this data-set, we first selected respondents who participated at $T_{2}, T_{3}$ and $T_{4}$ (regardless of being victimised, $n=4020$ ). After this selection, we weighted the data using the 16 demographic profiles of the Dutch adult population (2019). We finally selected respondents who were not victimised by VATs in the period $T_{1}$ to $T_{4}\left(n^{\text {non-victims }}=3245\right)$.

All results are based on weighted data (except Cronbach's alpha).

\section{Measures}

At each survey, gender, age, marital and employment status and education level are assessed. Questions about post-traumatic stress symptoms, coping self-efficacy and social acknowledgement were only administered to victims.

\section{Experiences with VATS}

At each survey, respondents were asked to indicate for each of the 21 listed potentially traumatic events, if they were exposed to this specific event in the past 12 months (1, no; 2 , yes) including the following VAT events:

(a) physical violence (sexual violence/sexual abuse (not online); online sexual violence/sexual abuse; robbery; physical violence, but not by own partner; physical violence by own partner);

(b) accidents (traffic accidents, disasters, fire, medical errors); and

(c) threats (serious threat; without the use of physical violence (not online); online serious threat, without use of physical violence).

The list also included events like (sudden) death of a (significant) other, (online) theft and serious illness categorised here as other stressful life events (SLEs). Participants were finally given the opportunity to report events in the previous 12 months that were not listed, which were recoded afterwards into existing or new categories. ${ }^{1}$

Lastly, they were asked when the (most drastic or stressful) event occurred (coded as 1 for 1 week ago to 8 for 7-12 months ago), and asked to rate the level of stress during the event (coded 1 for none to 5 for very much). To reduce the number of cells with low cell counts, both time since the event and stress during the event were dichotomised (time: 1 , up to 2 months ago $(1,2,3$, 4 and 5); 2, 3-12 months ago (6, 7 and 8); stress: 1 , not very stressful (1,2 and 3); 2, very stressful (4 and 5)).

\section{Anxiety and depression symptoms}

In all surveys, anxiety and depression symptoms were assessed using the five-item Mental Health Inventory: this scale covers symptoms during the past month on six-point Likert scales, such as 'This past month I felt very anxious' and 'I felt depressed and gloomy' ( 0 , never to 5 , continuously). ${ }^{11,12}$ After recoding the negative formulated items, the total scores were computed and multiplied by four (range 0 to 100), where lower scores indicate higher anxiety and depression symptom levels (all Cronbach's alpha of group $1^{\text {victims }}$, group $2^{\text {victims }}$ and non-victims $\geq 0.85$ ). A cut-off score of $\leq 59$ was used to identify respondents with moderate-severe anxiety and depression symptom levels. ${ }^{13}$

\section{Post-traumatic stress symptoms}

To examine PTSD symptomatology at $T_{2}$ and $T_{4}$, victims were asked to fill in the eight-item version of PTSD Checklist for DSM-5 $(\mathrm{PCL}-5)^{14,15}$ with the VAT event (reported in the same survey) 
in mind. When respondents reported two or more events, they were asked to focus on the most impactful or stressful VAT event when filling in the PCL-5. This event was presented on the screen. Examples of items are 'Feeling very upset when something reminded you of the stressful experience' and 'Loss of interest in activities that you used to enjoy'. The items of the PCL-5 have a five-point Likert scale (0, not at all to 4 , extremely) and examine symptoms across the four symptom clusters of PTSD according to DSM-5 and focus on symptoms in the past month (range 0 to 32 ). Higher scores reflect higher PTSD-symptom levels (Cronbach's alpha of group $1^{\text {victims }}$ and group $2^{\text {victims }} \geq 0$. 92). To identify victims with probable PTSD, a cut-off of $\geq 13$ was applied. ${ }^{16}$

\section{General mental health problems and physical problems}

The brief screening Problems and Help Inventarisation List ${ }^{17}$ was administered at all surveys to examine the prevalence of various problems such as general mental health problems, financial problems and physical problems. All respondents were asked to indicate for each of the problem types listed whether they experience these problems or not (1, yes; 2 , no). For the present study, data was extracted from the items 'psychological problems' (as a proxy for general mental health problems), and 'physical problems'.

\section{Coping self-efficacy}

To examine VAT-related coping self-efficacy among victims at $T_{2}$ and $T_{4}$, the seven-item Coping Self-Efficacy (CSE-7) ${ }^{18}$ measure was administered with items such as 'dealing with frightening images or dreams about the event' and 'being optimistic since the event'. The CSE-7 was administered in the same way as the PCL5. For each item, respondents rated their perceived self-efficacy level on a seven-point Likert scale (1, I am completely incapable of to 7, I am perfectly capable of; Cronbach's alpha of group $1^{\text {victims }}$ and group $2{ }^{\text {victims }} \geq 0.93$ ). Higher scores reflect higher coping self-efficacy levels (range 7-49). A cut-off of $\leq 28$, corresponding to (about) 10\% lowest scores, was used to identify victims with relatively low versus high coping self-efficacy levels.

\section{Social acknowledgement}

To assess event-related social acknowledgement among victims at $T_{2}$ and $T_{4}$, the five-item general disapproval scale of the Social Acknowledgment Questionnaire (SAQ) ${ }^{19}$ was administered, in the same way as the PCL-5 and CSE-7. The items have five-point answer categories ( 1 , totally disagree to 5 , totally agree). Examples of items are 'There is not enough sympathy for what happened to me' and 'Most people cannot understand what I went through' (both Cronbach's alpha of group $1^{\text {victims }}$ and group $2^{\text {victims }} \geq 0.85$ ). Higher scores reflect lower social acknowledgement levels (range 5-25). A cut-off of $\geq 17$, corresponding to (about) the $10 \%$ highest scores, was used to identify respondents with a high lack of social acknowledgement.

\section{Lack of emotional support}

In all surveys, lack of emotional support in response to problems was examined among all respondents with the eight-item subscale lack of emotional support of the Social Support List-Discrepancy (SSL-D). ${ }^{20,21}$ Examples of items are 'comfort you' and 'help you to clarify your problems'. The SSL-D items apply four-point Likert scales (1, I miss this, I would like it to happen more often to 4, It happens too often). Low scores reflect a higher lack of emotional support levels (range 8-32) (Cronbach's alpha of group $1^{\text {victims }}$, group $2^{\text {victims }}$ and non-victims $\geq 0.88$ ). A cut-off of $\leq 16$, corresponding to (about) the $10 \%$ lowest scores, was used to identify respondents with a high lack of emotional support.

\section{Statistical analyses}

Differences in characteristics between both victim groups were assessed using a chi-square test. Of the non-VAT-related characteristics of the non-victims at $T_{2}, T_{3}$ and $T_{4}$, we only examined differences in exposure to other events (SLEs) in the past 12 months and physical problems because age, education level, marital status and employment status follow a natural pattern (slight change) over a period of 3 years.

\section{Post-event differences between both victim groups}

To examine differences between both victim groups for the prevalence of post-event (for group $1^{\text {victims }}$ at $T_{2}$, and for group $2^{\text {victims }}$ at $T_{4}$ ) anxiety and depression symptoms, post-traumatic stress symptoms, general mental health problems, coping self-efficacy, lack of emotional support and social acknowledgement, multivariate logistic regression analyses were conducted. To test differences between both victim groups in a rigorous way and to rule out alternative explanations for differences between the two groups as much as possible, we controlled for characteristics that differed between both groups not only at a $P<0.05$ level but also at a $P \leq 0.10$ level (see Table 1), for example gender, number of different VAT events in the past 12 months and general mental health problems in the year before.

To examine differences in mean scores for post-event anxiety and depression symptoms, post-traumatic stress symptoms, coping self-efficacy, lack of emotional support and social acknowledgement between both victim groups, mixed-effects models were conducted with the same control variables as in the logistic regression analyses.

\section{Differences in incidence (change) between both victim groups}

Differences in the incidence of anxiety and depression symptoms, general mental health problems and lack of social support were conducted with similar logistic regression analyses (the incidence of other variables could not be calculated). The incidence was calculated by dividing the number of respondents with post-event symptoms, problems and lack of support among those without pre-event symptoms, problems and lack of support, by the total number of the victim group.

\section{Differences after and before the outbreak among non-victims}

To examine the extent to which the prevalence of anxiety and depression symptoms, general mental health problems and lack of social support among non-victims changed after the outbreak $\left(T_{4}\right)$ compared with before the outbreak $\left(T_{2}\right)$, repeated measures multivariate logistic regression analyses were performed. In the analyses, we controlled for $T_{2^{-}}$and $T_{4}$-related demographics and reported other potentially traumatic or SLEs. Mixed-effects models were conducted to examine differences in mean scores of symptoms, problems, and support at $T_{2}$ and $T_{4}$ on the same (time-dependent) variables.

All analyses were performed with IBM SPSS version 26.

\section{Results}

\section{Characteristics of victims and non-victims}

The characteristics of the two victim groups, including pre-event are represented in Table 1 . Table 1 shows that these two groups differed in gender, number of different VAT events, and the prevalence of general mental health problems at a $P \leq 0.10$ level.

The characteristics of the non-victims at $T_{2}$ and $T_{4}$ are presented in Table 2. During the 12 months before $T_{4}$, non-victims were significantly less often exposed to SLEs than in the 12 months before $T_{2}(29.7 \%$ v. $24.8 \%$, adjusted odds ratio $(\mathrm{aOR})=0.74$, 
Table 1 Characteristic victims before and after the coronavirus disease 2019 (COVID-19) outbreak ${ }^{\mathrm{a}}$

\begin{tabular}{|c|c|c|c|c|c|}
\hline & \multicolumn{2}{|c|}{ Victimised in 12 months before } & \multirow[b]{3}{*}{$\chi^{2}$} & \multirow[b]{3}{*}{ d.f. } & \multirow[b]{3}{*}{$P$} \\
\hline & $\begin{array}{l}\text { March } 2019\left(T_{2}\right) \\
\quad(n=421)\end{array}$ & $\begin{array}{c}\text { March } 2021\left(T_{4}\right) \\
\quad(n=319)\end{array}$ & & & \\
\hline & $n(\%)$ & $n(\%)$ & & & \\
\hline \multicolumn{6}{|l|}{ Gender } \\
\hline Men & $206(48.9)$ & $178(55.8)$ & \multirow[t]{2}{*}{3.429} & \multirow[t]{2}{*}{1} & \multirow[t]{2}{*}{0.064} \\
\hline Women & $215(51.1)$ & $141(44.2)$ & & & \\
\hline \multicolumn{6}{|l|}{ Age, years } \\
\hline $18-34$ & $116(27.6)$ & $102(32.0)$ & \multirow[t]{4}{*}{2.075} & \multirow[t]{4}{*}{3} & \multirow[t]{4}{*}{0.557} \\
\hline $35-49$ & $121(28.7)$ & 87 (27.3) & & & \\
\hline $50-64$ & $107(25.4)$ & $80(25.1)$ & & & \\
\hline 65 or older & 77 (18.3) & $50(15.7)$ & & & \\
\hline \multicolumn{6}{|l|}{ Education level $^{\mathrm{b}}$} \\
\hline Low & $94(22.3)$ & 65 (20.4) & \multirow[t]{3}{*}{0.628} & \multirow[t]{3}{*}{2} & \multirow[t]{3}{*}{0.731} \\
\hline Medium & $147(34.8)$ & 119 (37.3) & & & \\
\hline High & $181(42.9)$ & $135(42.3)$ & & & \\
\hline \multicolumn{6}{|l|}{ Employed } \\
\hline No & $168(39.9)$ & $134(42.0)$ & \multirow[t]{2}{*}{0.332} & \multirow[t]{2}{*}{1} & \multirow[t]{2}{*}{0.565} \\
\hline Yes & $253(60.1)$ & $185(58.0)$ & & & \\
\hline \multicolumn{6}{|l|}{ Married } \\
\hline Yes & $172(40.9)$ & $117(36.7)$ & \multirow[t]{2}{*}{1.331} & 1 & 0.249 \\
\hline No & $249(59.1)$ & 202 (63.3) & & & \\
\hline Physical proble & & & & & \\
\hline Yes & $227(53.8)$ & $181(56.7)$ & 0.638 & 1 & 0.424 \\
\hline No & $195(46.2)$ & 138 (43.3) & & & \\
\hline Other PTE/SLES & in past 12 month & & & & \\
\hline No & $202(47.9)$ & $156(48.9)$ & 0.078 & 1 & 0.780 \\
\hline Yes & $220(52.1)$ & $163(51.1)$ & & & \\
\hline Period VAT eve & & & & & \\
\hline $\begin{array}{l}\text { Up to } 2 \\
\text { months ago }\end{array}$ & $148(36.3)$ & $115(38.3)$ & 0.314 & 1 & 0.575 \\
\hline 3-12 months & $260(63.7)$ & $185(61.7)$ & & & \\
\hline Stress during $\mathrm{V}$ & $\mathrm{T}_{\text {T event }}^{\mathrm{C}}$ & & & & \\
\hline Low & $241(59.2)$ & $161(53.8)$ & 2.025 & 1 & 0.155 \\
\hline High & $166(40.8)$ & $138(46.2)$ & & & \\
\hline Different types & f VATs ${ }^{d}$ in past 12 n & honth & & & \\
\hline 1 & $350(83.1)$ & $249(78.1)$ & 3.035 & 1 & 0.081 \\
\hline 2 or more & 71 (16.9) & 70 (21.9) & & & \\
\hline VAT in year bef & & & & & \\
\hline No & $304(72.0)$ & $213(66.8)$ & 2.389 & 1 & 0.122 \\
\hline Yes & $118(28.0)$ & $106(33.2)$ & & & \\
\hline Anxiety and de & ressions symptom y & ear before & & & \\
\hline No & $308(73.2)$ & $223(69.9)$ & 0.948 & 1 & 0.330 \\
\hline Yes & $113(26.8)$ & $96(30.1)$ & & & \\
\hline General mental & health problems yea & r before & & & \\
\hline No & $339(80.5)$ & $241(75.5)$ & 2.649 & 1 & 0.104 \\
\hline Yes & $82(19.5)$ & 78 (24.5) & & & \\
\hline Lack support ye & ar before & & & & \\
\hline No & $346(82.2)$ & $267(83.7)$ & 0.293 & 1 & 0.589 \\
\hline Yes & 75 (17.8) & 52 (16.3) & & & \\
\hline $\begin{array}{l}\text { PTE, potentially tra } \\
\text { accidents and/or s } \\
\text { a. As a result of w } \\
\text { b. Low, primary sc } \\
\text { medium, higher se } \\
\text { high school); inter! } \\
\text { vocational educati } \\
\text { of Statistics Nethe } \\
\text { c. Respondents wh } \\
\text { to have the most s } \\
\text { question. Of all } 74 \\
\text { mind. They were o } \\
\text { d. Three types of }\end{array}$ & $\begin{array}{l}\text { matic event; SLE, stres } \\
\text { rious threat. } \\
\text { ghting, the numbers ( } n \\
\text { ool, intermediate secon } \\
\text { ondary education/prep } \\
\text { ediate, vocational educ } \\
\text { n, (USA: college, univers } \\
\text { ands (CBS). } \\
\text { were confronted with r } \\
\text { essful VAT event in the } \\
\text { VAT victims, } 33 \text { answer } \\
\text { itted from these analys } \\
\text { ATS were distinguished: }\end{array}$ & 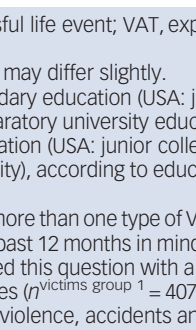 & $\begin{array}{l}\text { Dosure to } \\
\text { unior high } \\
\text { ation (US } \\
\text { ge); high, } \\
\text { ation leve } \\
\text { AT event, } \\
\text { d when an } \\
\text { theft-rela } \\
n^{\text {victims } 8}\end{array}$ & $\begin{array}{l}\text { violer } \\
\text { in sche } \\
\text { SA: se } \\
\text { t, high } \\
\text { el cate } \\
\text { t, were } \\
\text { nswer } \\
\text { ated e } \\
\text { group } 2\end{array}$ & $\begin{array}{l}\text { nce, } \\
\text { ool); } \\
\text { nior } \\
\text { er } \\
\text { egories } \\
\text { e asked } \\
\text { ring the } \\
\text { event in } \\
=300 \text { ). } \\
=\text { ats. }\end{array}$ \\
\hline
\end{tabular}

95\% CI 0.67-0.82, $P<0.001)$. In addition, the prevalence of physical problems decreased significantly $(30.7 \%$ v. $29.6 \%, \mathrm{aOR}=0.992$, 95\% CI 0.862-0.988, $P=0.020$ ) among non-victims.

\section{Differences between the two victim groups}

Table 3 shows that respondents victimised after the outbreak of COVID-19 have a significant higher prevalence (37.6\% v. 26.4\%)

\begin{tabular}{|c|c|c|}
\hline & \multicolumn{2}{|l|}{ Non-victims $(n=3245)$} \\
\hline & March $2019\left(T_{2}\right), n(\%)$ & March $2021\left(T_{4}\right), n(\%)$ \\
\hline \multicolumn{3}{|l|}{ Gender } \\
\hline Men & $1585(48.8)$ & 1585 (48.8) \\
\hline Women & $1661(51.2)$ & $1661(51.2)$ \\
\hline \multicolumn{3}{|l|}{ Age, years } \\
\hline 18-34 & $821(25.3)$ & 706 (21.7) \\
\hline $35-49$ & $758(23.4)$ & 749 (23.1) \\
\hline $50-64$ & $844(26.0)$ & $836(25.8)$ \\
\hline 65 or older & $822(25.3)$ & 955 (29.4) \\
\hline \multicolumn{3}{|l|}{ Education ${ }^{b}$} \\
\hline Low & $818(25.2)$ & $781(24.1)$ \\
\hline Medium & $1180(36.4)$ & $1143(35.2)$ \\
\hline High & $1248(38.4)$ & $1321(40.7)$ \\
\hline \multicolumn{3}{|l|}{ Employed } \\
\hline No & $1495(46.1)$ & 1499 (46.2) \\
\hline Yes & 1750 (53.9) & $1746(53.8)$ \\
\hline \multicolumn{3}{|l|}{ Married } \\
\hline Yes & $1632(50.3)$ & $1670(51.5)$ \\
\hline No & $1613(49.7)$ & 1575 (48.5) \\
\hline \multicolumn{3}{|c|}{ Physical problems } \\
\hline Yes & 997 (30.7) & $960(29.6)$ \\
\hline No & $2248(69.3)$ & 2285 (70.4) \\
\hline \multicolumn{3}{|l|}{ Other PTE/SLE } \\
\hline No & $2281(70.3)$ & $2440(75.2)$ \\
\hline Yes & $964(29.7)$ & $805(24.8)$ \\
\hline \multicolumn{3}{|c|}{$\begin{array}{l}\text { PTE, potentially traumatic event; SLE, stressful life event. } \\
\text { a. As a result of weighting, the numbers (n) may differ slightly. } \\
\text { b. Low, primary school, intermediate secondary education (USA: junior high school); } \\
\text { medium, higher secondary education/preparatory university education (USA: senior } \\
\text { high school); intermediate, vocational education (USA: junior college); high, higher } \\
\text { vocational education, (USA: college, university), according to education level categories } \\
\text { of Statistics Netherlands (CBS). }\end{array}$} \\
\hline
\end{tabular}

and incidence ( $13.8 \%$ v. $8.8 \%)$ of anxiety and depression symptoms, and lower mean scores (i.e. higher levels) of these symptoms (64.1 v. 69.6, Cohens $d=0.30$ ) than respondents victimised before the outbreak, while controlling for gender, the number of different VAT events in the past 12 months and general mental health problems in the year before.

In addition, they also have a significant higher prevalence of general mental health problems $(30.4 \% v .18 .8 \%)$ and a significant higher prevalence of probable PTSD (28.1\% v. 19.9\%). Adults victimised in the year after the outbreak of COVID-19 had also significant higher post-traumatic symptom scores (Cohen's $d=$ $0.25)$ than victims before the outbreak. In addition, this group had a significant lower prevalence of high coping self-efficacy levels $(81.0 \%$ v. $89.4 \%)$ than adults victimised before this pandemic, but mean scores did not differ significantly between both groups. No significant differences were found between the two victim groups in lack of emotional support and social acknowledgement.

\section{Differences after and before the outbreak among non-victims}

Repeated measures multivariate logistic regression analyses (not shown in table) among the non-victims $(n=3245)$ revealed a significantly higher prevalence of anxiety and depression symptoms at $T_{4}(15.0 \%)$ than at $T_{2}(14.5 \%: \mathrm{aOR}=1.14,95 \% \mathrm{CI} 1.02-1.26$, $P=0.015)$. No significant $(P<0.05)$ differences in general mental health problems $(9.5 \%$ v. $9.2 \%)$, or lack of emotional support $(8.2 \%$ v. $8.7 \%)$ were found. Mixed-effects models showed no significant differences in anxiety and depression symptom levels between $T_{4}$ and $T_{2}\left(T_{2}\right.$ mean 75.6, s.d. $=15.95 ; T_{4}$ mean 75.40 , s.d. $\left.=15.70\right)$ and no differences in lack of emotional support levels $\left(T_{2}\right.$ mean 22.1 , s.d. $=3.24 ; T_{4}$ mean 21.9 , s.d. $=3.28$ ). 
Table 3 Differences between victims before and victims after the coronavirus disease 2019 (COVID-19) outbreak ${ }^{\mathrm{a}}$

\begin{tabular}{|c|c|c|c|c|c|}
\hline & \multicolumn{2}{|c|}{ Victimised in 12 months before } & \multirow[b]{2}{*}{ aOR $(95 \% \mathrm{Cl})$} & \multirow[b]{2}{*}{$F(1,739)$} & \multirow[b]{2}{*}{$P$} \\
\hline & March $2019\left(T_{2}\right)(n=421)$ & March $2021\left(T_{3}\right)(n=319)$ & & & \\
\hline \multicolumn{6}{|c|}{ Anxiety and depression symptoms ${ }^{b}$} \\
\hline score, mean (s.d.) & $69.6(19.4)$ & $64.1(19.8)$ & & \multirow[t]{3}{*}{11.228} & 0.001 \\
\hline Prevalence, $n(\%)$ & $111(26.4)$ & $120(37.6)$ & $1.63(1.15-2.29)$ & & 0.005 \\
\hline Incidence, $n(\%)$ & $37(8.8)$ & $44(13.8)$ & $1.64(1.02-2.61)$ & & 0.039 \\
\hline \multicolumn{6}{|c|}{ General mental health problems } \\
\hline score, mean (s.d.) & n.a. & n.a. & \multirow{2}{*}{\multicolumn{2}{|c|}{$1.92(1.26-2.92)$}} & \\
\hline Prevalence, $n(\%)$ & $79(18.8)$ & $97(30.4)$ & & & 0.002 \\
\hline Incidence, $n(\%)$ & $31(7.4)$ & $36(11.3)$ & \multicolumn{2}{|l|}{$1.56(0.93-2.61)$} & 0.089 \\
\hline \multicolumn{6}{|c|}{ Post-traumatic stress symptoms ${ }^{c}$} \\
\hline score, mean (s.d.) & $5.6(6.8)$ & $7.4(7.9)$ & \multirow{3}{*}{$1.48(1.02-2.14)$} & \multirow[t]{3}{*}{7.636} & 0.006 \\
\hline Prevalence, $n$ (\%) & $81(19.9)$ & $84(28.1)$ & & & \multirow[t]{2}{*}{0.040} \\
\hline Incidence, $n$ (\%) & n.a. & n.a. & & & \\
\hline \multicolumn{6}{|l|}{ Coping self-efficacy ${ }^{c}$} \\
\hline Mean score & $39.4(9.6)$ & $38.1(9.9)$ & \multirow{3}{*}{$0.55(0.35-0.87)$} & \multirow[t]{3}{*}{0.795} & 0.373 \\
\hline Prevalence, $n(\%)$ & $364(89.4)$ & $243(81.0)$ & & & \multirow[t]{2}{*}{0.011} \\
\hline Incidence, $n(\%)$ & n.a. & n.a. & & & \\
\hline \multicolumn{6}{|c|}{ Lack of emotional support } \\
\hline Score, mean (s.d.) & $20.4(4.0)$ & $20.5(4.2)$ & & \multirow[t]{3}{*}{0.633} & 0.427 \\
\hline Prevalence, $n$ (\%) & $73(17.3)$ & $57(17.9)$ & $0.98(0.66-1.45)$ & & 0.913 \\
\hline Incidence, $n(\%)$ & $38(9.0)$ & $28(8.8)$ & $0.94(0.56-1.58)$ & & 0.822 \\
\hline \multicolumn{6}{|c|}{ Lack social recognition c,d } \\
\hline score, mean (s.d.) & $10.4(4.7)$ & $11.2(4.7)$ & & \multirow[t]{3}{*}{2.422} & 0.120 \\
\hline Prevalence, $n(\%)$ & $37(9.6)$ & 41 (14.3) & $1.44(0.88-2.35)$ & & 0.143 \\
\hline Incidence, n (\%) & n.a. & n.a. & & & \\
\hline \multicolumn{6}{|c|}{ 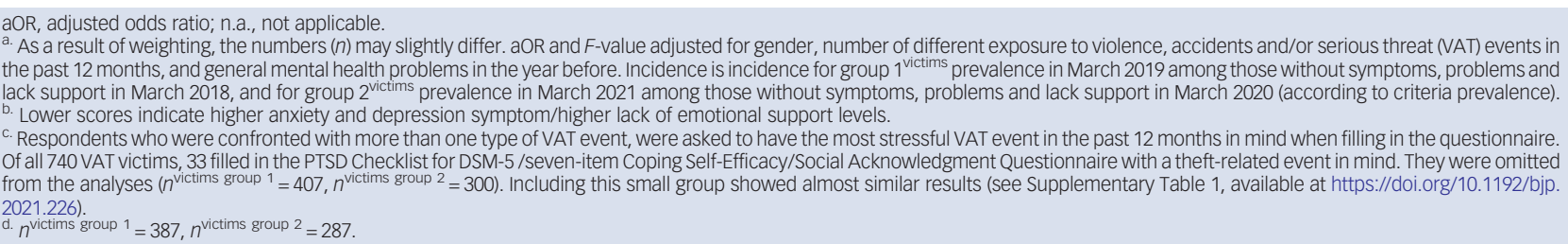 } \\
\hline
\end{tabular}

\section{Differences between victims and non-victims}

The prevalence of moderate-severe anxiety and depression symptom levels, general mental health problems and high lack of emotional support were significantly more prevalent among victims than among non-victims in the same survey, when controlling for demographics and other SLEs (2019: $\mathrm{aOR}^{\text {anxiety and }}$ depression symptoms $=1.84,95 \% \mathrm{CI} 1.43-2.37, P<0.001 ; \mathrm{aOR}^{\text {general }}$ mental health problems $=2.01,95 \%$ CI 1.51-2.66, $P<0.001$; and $\mathrm{aOR}^{\text {lack }}$ of emotional support $=2.17,95 \%$ CI $1.63-2.90, \quad P<0.001$, respectively; 2021: $\mathrm{aOR}^{\text {anxiety and depression symptoms }}=2.77,95 \% \mathrm{CI}$ 2.13-3.60 $P<0.001 ; \mathrm{aOR}^{\text {general mental health problems }}=3.34,95 \% \mathrm{CI}$ 2.51-4.45, $\quad P<0.001$; and $\mathrm{aOR}^{\text {lack }}$ of emotional support $=2.23$, 95\% CI 1.72-2.90, $P<0.001$, respectively).

\section{Post hoc control analyses}

Respondents who were victimised in both study periods were randomly allocated to group $1^{\text {victims }}$ or to group $2^{\text {victims }}$. Although both victim groups did not significantly differ in exposure to VATs in the year before, to rule out the possibility that the described results can be attributed to (non-significant) differences in exposure to VATs in the year before $(28.0 \% v .33 .2 \%)$ we reanalysed the data by adding this variable to the list of control variables. No relevant differences to the results presented above emerged.

In addition, analyses of the prevalence of specific VAT-related events showed that group $1^{\text {victims }}$ significantly more often $(P<$ $0.05)$ was exposed to traffic accidents (36.1\% v. 29.1\%) than group $2^{\text {victims }}$, but that group $2^{\text {victims }}$ was significant more often exposed to physical violence (not by own partner): $17.6 \%$ v. $9.7 \%$ (see Supplementary Table 2 available at https://doi.org/10.1192/bjp. 2021.226). There was a statistical trend $(P<0.10)$ that group $2^{\text {victims }}$ were also more often exposed to robberies (6.3\% v. 3.3\%). However, the fact that group $2^{\text {victims }}$ was more often exposed to these events did not explain the differences in anxiety and depression symptoms, general mental health, PTSD symptomatology and coping self-efficacy. Adding these two variables to the list of control variables did not change results. Both groups did not significantly differ in the distribution of (the most stressful) VAT event when filling in the PCL-5, CSE-7 and SAQ $\left(\chi^{2}=12.21\right.$, d.f. $=12$, $P=0.429$, see Supplementary Table 3).

\section{Discussion}

The general aim of the present study was to examine the extent to which the COVID-19 pandemic and all related disruptions hindered the recovery of victims of potentially traumatic events. For this purpose, we compared the mental health, including PTSD symptomatology, trauma-related coping self-efficacy, and lack of emotional support and social acknowledgement among adults victimised during this pandemic (in the period March 2020-March 2021) with adults victimised before this pandemic (March 2018March 2019). We focused on VATs.

Findings showed the following clear patterns. First, this pandemic partly hindered the recovery of victims as indicated by a significant higher prevalence and incidence of anxiety and depression symptoms, higher prevalence of general mental health problems, a lower prevalence of high coping self-efficacy and higher posttraumatic symptom scores among adult victims 12 months after the outbreak of COVID-19 compared with adults victimised in the same period before the outbreak. Second, no indications were found that this pandemic had a negative effect on emotional 
support and event-related social acknowledgement: both victim groups did not differ in related prevalence, incidence and/or mean scores, although they more often lacked emotional support than non-victims at both March 2019 and March 2021. These findings suggest that the decreased recovery among victims after the outbreak cannot be attributed to a decrease of emotional support, but to other stressors related to this pandemic (such as lockdowns, infection, health risks, unemployment risk).

Although there was no significant difference in the mean scores for anxiety and depression symptoms, the proportion of nonvictims scoring above the cut-off score for elevated symptom levels slightly increased between before and after the COVID-19 outbreak ( $14.5 \%$ to $15.0 \%$ ), whereas the prevalence of physical problems slightly decreased. The finding that such trivial differences gain statistical significance is most probably related to the large sample size $(n=3245)$. Among non-victims, no significant differences between both time periods were found with respect to general mental health problems and lack of emotional support. These results indicate that this pandemic particularly affected victims of VATs. Previous population-based research in the Netherlands found no indications for an increase in the prevalence and incidence of mental health problems among the general population until November-December 2020 compared with prepandemic levels, in contrast to an increase in loneliness. ${ }^{22,23}$

\section{Practical relevance}

A large number of COVID-19-related studies are aimed at identifying groups that are at risk for mental health problems because of this pandemic. These insights may guide the development and implementation of programmes and interventions to target these groups at risk so as to prevent or reduce (ongoing) COVID-19related mental health problems. Victims of VATs are already at risk for mental health problems in 'normal' times, but this study clearly shows that being a victim of these events during this pandemic amplifies this risk. For mental healthcare professionals, general practitioners and victim services, screening and monitoring of victims' mental health are important measures to determine if and which further interventions are needed. Our results indicate that during this pandemic these measures become even more important, also because lower coping self-efficacy levels were observed that increase the risk for mental health problems. ${ }^{4,24}$

These findings stress the importance of securing the accessibility of mental healthcare services that was hindered during this pandemic because of social distancing measures, for instance, by providing virtual 'walk-in' clinics/victim services. ${ }^{25}$ Importantly, as no significant differences between the two victim groups in lack of emotional support and social acknowledgement were found, it is not plausible to attribute the amplified risk to diminished social support levels. However, like in pre-pandemic times, victims more often lack emotional support than non-victims. It therefore remains equally important to address the lack of social support among victims.

\section{Strength and limitations}

To the best of our knowledge, this is the first comparative longitudinal study assessing the impact of the COVID-19 pandemic on the mental health, coping self-efficacy and social support of victims of VATs. Major strengths are the use of a large longitudinal population-based random sample, the high response rates of each survey, the weighting of data to optimise the representativeness of the results, the use of validated questionnaires, analyses in which differences between both victim groups were controlled for, and the inclusion of non-victims assessed in the same period. However, some limitations need to be clarified.
Our study did not include children and adolescents, we did not examine the effects of this pandemic on respondents who were victimised by earlier potentially traumatic events such as adverse childhood experiences, and no clinical interviews were conducted to examine mental disorders among victims and non-victims. We have no information about the frequency of events. Given the aim of the present study, we did not focus on acute, life-threatening and catastrophic COVID-19-related events. ${ }^{26,27}$ In addition, we did not examine other relevant aspects of mental health such as burnout.

The main conclusions that can be drawn from the results is that adults victimised by VATs in the year following the outbreak of COVID-19 more often have post-traumatic stress symptoms, anxiety and depression symptoms, and general mental health problems, and had lower coping self-efficacy levels than those victimised before the outbreak.

Peter G. van der Velden (D), Centerdata, the Netherlands and Tilburg University's Network on Health and Labor (NETHLAB), Tilburg University, the Netherlands; Carlo Contino, Fonds Slachtofferhulp, the Netherlands; Marcel Das, Centerdata, the Netherlands and Tilburg School of Economics and Management, Tilburg University, the Netherlands; Joost Leenen, Centerdata, the Netherlands; Lutz Wittmann International Psychoanalytic University Berlin, Germany

Correspondence: Peter G. van der Velden. Email: pg.vandervelden@tilburguniversity. edu

First received 3 Oct 2021, final revision 8 Dec 2021, accepted 21 Dec 2021

\section{Supplementary material}

To view supplementary material for this article, please visit https://doi.org/10.1192/bjp.2021. 226

\section{Data availability}

The data of the surveys in 2018, 2019, 2020 and 2021 of the VICTIMS study are, after registration, freely available from the LISS dataarchive (see https://www. dataarchive.lissdata.nl, in English, assembled study 208) for researchers, like all other studies conductedwith the LISS panel. The data of the survey conducted in 2021 will be added to the data archive soon.

\section{Author contributions}

P.G.v.d.V. and C.C. conceived and designed the study in collaboration with M.D. and L.W. The data analyses was performed by P.G.V.d.V. in cooperation with M.D. and L.W. All authors contributed to the data interpretation. P.G.v.d.V. Wrote the first draft. All authors critically revised the first draft, and all authors approved the final version of the article to be published.

\section{Funding}

This study is funded by Fonds Slachtofferhulp, the Netherlands (50006/VICTIMS).

\section{Declaration of interest}

\section{References}

1 van der Velden PG, Komproe I, Contino C, de Bruijne M, Kleber RJ, Das M, et al. Which groups affected by potentially traumatic events (PTES) are most at risk for a lack of social support? A prospective population-based study on the 12month prevalence of PTEs and risk factors for a lack of post-event social support. PLOS ONE 2020; 15: e0232477.

2 Koenen KC, Ratanatharathorn A, Ng L, McLaughlin KA, Bromet EJ, Stein DJ, et al. Posttraumatic stress disorder in the World Mental Health Surveys. Psychol Med 2017; 47: 2260-74.

3 Benight CC, Bandura A. Social cognitive theory of posttraumatic recovery: the role of perceived self-efficacy. Behav Res Ther 2004; 42: 1129-48. 
4 Luszczynska A, Benight CC, Cieslak R. Self-efficacy and health-related outcomes of collective trauma: a systematic review. Euro Psychologist 2009; 14 $51-62$

5 Kaniasty K, Norris FH. Longitudinal linkages between perceived social support and posttraumatic stress symptoms: sequential roles of social causation and social selection. J Trauma Stress 2008; 21: 274-81.

6 van der Velden PG, Contino C, Marchand M, Das M, Schut H. Does pre-even lack of emotional support increase the risk of post-event PTSD, anxiety, depression symptoms and lack of support? A comparative population-based study among victims of threat and violence. J Anxiety Disord 2020; 75: 102269

7 Robinson E, Sutin AR, Daly M, Jones A. A systematic review and meta-analysis of longitudinal cohort studies comparing mental health before versus during the COVID-19 pandemic. J Affect Disord 2022; 296: 567-76.

8 Hobfoll SE. Conservation of resources. A new attempt at conceptualizing stress. Am Psychol 1989; 44: 513-24.

9 Hobfoll SE. Social and psychological resources and adaptation. Rev Gen Psychol 2002; 6: 307-24.

10 Scherpenzeel A, Das M. True longitudinal and probability based internet panels: evidence from The Netherlands. In Social and Behavioral Research and the Internet: Advances in Applied Methods and Research Strategies (eds M Das, P Ester and L Kaczmirek): 77-104. Taylor \& Francis, 2011.

11 Ware JE, Sherbourne CD. The MOS 36-item short-form health survey, SF-36: I. Conceptual framework and item selection. Med Care 1992; 30: 473-483.

12 Means-Christensen AJ, Arnau RC, Tonidandel AM, Bramson R, Meagher MW An efficient method of identifying major depression and panic disorder in primary care. J Behav Med 2005; 28: 565-572.

13 Driessen M. Een beschrijving van de $\mathrm{MHI}-5$ in De Gezondheidsmodule van het Permanent Onderzoek Leefsituatie [A Description of the $\mathrm{MHI}-5$ in the Health Module of Permanent Research of Living Conditions, POLS]. Statistics Netherlands, 2011.

14 Price M, Szafranski DD, van Stolk-Cooke K, Gros DF. Investigation of abbreviated 4 and 8 item versions of the PTSD Checklist 5. Psychiatry Res 2016; 239 124-30.

15 Weathers FW. Posttraumatic stress disorder checklist. In Encyclopedia of Psychological Trauma (eds G Reyes and JD Elhai): 491-94. Wiley, 2008.

16 Pereira-Lima K, Loureiro SR, Bolsoni LM, Apolinario da Silva TD, Osório FL. Psychometric properties and diagnostic utility of a Brazilian version of the PCL5 (complete and abbreviated versions). Eur J Psychotraumatol 2019; 10 : 1581020 .

17 van der Velden PG, Das M, Contino C, van der Knaap LM. From health to financial problems: multiproblems among victims of partner and non-partne physical violence, and matched nonvictims. J Interpers violence 2019; 5: 886260519885915

18 Bosmans MWG, Komproe IH, Van der Knaap LM, Benight CC, van der Velden PG. Assessing perceived ability to cope with trauma: a multigroup validity study of a trauma-related coping self-efficacy scale. Eur J Psychol Assess 2017; 33: 55-64.

19 Maercker A, Müller J. Social acknowledgment as a victim or survivor: a scale to measure a recovery factor of PTSD. J Trauma Stress 2004; 17: 345-51.

20 Bridges KR, Sanderman R, van Sonderen E. An English language version of the social support list: preliminary reliability. Psychol Rep 2002; 90: 1055-58.

21 van Sonderen E. Het meten van Sociale Steun met de Sociale Steun Lijst -Interacties SSL-I en Sociale Steun Lijst -Discrepanties, SSL-D: een handleiding (Tweede herziene druk) [The measurement of social support with the Social Suppport List - Interactions (SSL-I) and Discrepancies (SSL-D]. Research Institute SHARE RUG, 2012

22 van der Velden PG, Hyland P, Contino C, von Gaudecker HM, Muffels R, Das M. Anxiety and depression symptoms, the recovery from symptoms, and loneliness before and after the COVID-19 outbreak among the general population. Findings from a Dutch population-based longitudinal study. PLOS ONE 2021; 16: e0245057.

23 van der Velden PG, Marchand M, Das M, Muffels R, Bosmans M. The prevalence, incidence and risk factors of mental health problems and mental health services use before and 9 months after the COVID-19 outbreak among the general Dutch population. A 3-wave prospective study. medRxiv [Preprint] 2021. Available from: https://doi.org/10.1101/2021.02.27.21251952.

24 Bosmans MWG, van der Velden PG. Cross-lagged associations between posttraumatic stress symptoms and coping self-efficacy in long-term recovery: a four-wave comparative study. Soc Sci Med 2017; 193: 33-40.

25 Matthewman S, Spencer S, Lavergne MR, McCracken RK, Hedden L. An environmental scan of virtual "walk-in" clinics in canada: comparative study. Med Internet Res 2021; 23: e27259.

26 Norrholm SD, Zalta A, Zoellner L, Powers A, Tull MT, Reist C, et al. Does COVID19 count? Defining Criterion A trauma for diagnosing PTSD during a global crisis. Depress Anxiety 2021; 38: 882-85.

27 Bridgland VME, Moeck EK, Green DM, Swain TL, Nayda DM, Matson LA, et al. Why the COVID-19 pandemic is a traumatic stressor. PLOS ONE 2021; 16: e0240146. 